\title{
CHRONICLES OF MEDICAL HISTORY IN AFRICA
}

\section{GREAT TEACHING HOSPITALS OF AFRICA: KORLE BU TEACHING HOSPITAL, GHANA}

\author{
Dr. O.S Michael \\ Department of Pharmacology and Therapeutics, \\ University of Ibadan. \\ E-mail: micobaro@yahoo.com
}

"The student of medicine has his place in the hospital as part of its machinery just as much as he has in the anatomical laboratory, and ... to combine successfully in bis education practice with science, the academic freedom of the university must be transplanted to the hospital."

- William Osler

Universities are the citadels of knowledge; they are the peaks of human civilization, the most beautiful creation of our collective intellect as a species. The greatness and value of any society is a direct measure of the greatness of her Ivory towers. Chronicles of medical history in Africa takes a look at the institutions where almost all discoveries in medicine and medical sciences originate- the teaching hospitals. This article is drawn from several original documents downloaded from the internet. While teaching hospitals in Nigeria are amongst the greatest teaching hospitals in Africa, we shall feature them in future editions of this journal starting with the University College Hospital Ibadan in the December 2009 edition.

A teaching hospital is a hospital that provides clinical education and training to future and current doctors, nurses, and other health professionals, in addition to delivering medical care to patients. They are generally affiliated with medical schools or universities (hence the alternative term university hospital), and may be owned by a university or may form part of a wider regional or national health system. Some teaching hospitals also have a commitment to research and are centres for experimental, innovative and technically sophisticated services.

In the medieval Islamic world, al-Nuri hospital, built by the famous Nur ad-Din Zanqi, was made a teaching hospital and renowned physicians taught there. The hospital's medical school is said to have had elegant rooms, and a library which many of its books were donated by Zangi's physician, Abu al-Majid al-Bahili. A number of Muslim physicians and physicists graduated from there. Among the well-known students are Ibn Abi Usaybi'ah (1203-1270), the famous medical historian, and 'Ala ad-Din Ibn al-Nafis (d. 1289) whose discovery of pulmonary circulation and the lesser circulatory system marked a new step in the better understanding of human physiology and was the earliest explanation until Miguel Servet (1553).
William Harvey was appointed physician to St Bartholomew's hospital in 1609 and Lumieian lecturer at the College of Physicians. In 1658 he published his celebrated treatise, Exercitatio Anatomica de Motu Cordis et Sanguinis, in which he expounded his views of the circulation of the blood.

\section{Ghana}

Ghana, with an area of 238,537 square kilometers and a population of about 16.5 million (1994 estimate), lies along the west coast of Africa. For administrative purposes, the country is divided into ten regions, and one hundred and ten administrative districts. There are "four main categories of health care delivery systems in Ghana - the public, private-for-profit, private-notfor-profit, and traditional systems. Since the 1970s, the government of Ghana has gradually moved towards greater decentralization of the health system, creating a new Ghana Health Service (GHS), and providing management teams in hospitals at various levels greater flexibility in allocating resources according to their own priorities, within the overall context of the national policy. As part of this general reform of its health sector, the two teaching hospitals in Ghana, namely, the Korle Bu Hospital (KBU), and the Komfo Anokye Teaching Hospital (KATH), have also been encouraged by the Government of Ghana to become "selfgoverning". Korle Bu teaching hospital holds a very prominent place in the history of medical care in Ghana and the West African sub-region.

\section{The University of Ghana}

The KBU, with nearly 1600 beds, functions as the teaching hospital for the University of Ghana Medical School. The University of Ghana is the oldest and largest of the seven Ghanaian public Universities. It was founded in 1948 as the University College of the Gold Coast, and was originally an affiliate college of the University of London, which supervised its academic programs and awarded degrees. It gained full university status in 1961, and now has nearly 42,000 students. The original emphasis was on the liberal arts, social sciences, basic science, agriculture, and medicine, but (partly as the result of a national educational reform program) the curriculum was expanded to provide more technology-based and vocational courses and postgraduate training. The University is mainly based at Legon, about twelve kilometres northeast of the centre of Accra. The medical school is in Korle bu, with a teaching hospital and secondary campus in the city of Accra. 
Korle Bu Hospital has three primary goals: the provision of high-quality medical care, teaching (including the training of students in medicine, nursing, pharmacy, and a variety of other para-clinical and technical disciplines), and research. The four management functions of the hospital are: governance, general management, financial management, and human resource management. Governance refers to the function of defining the overall mission of the hospital, setting broad strategic goals, managing the hospital's assets, and bearing ultimate responsibility for the hospital's operational policies. General management refers to the responsibilities involved in the day-today running of the hospital and the discharge of the functions defined by the mission statement. Financial management refers to the generation of resources for the running of the hospital, and the proper planning, accounting, and allocation of these resources. Human resource management refers to the training and management of the various categories of hospital personnel.

\section{Sir Frederick Gordon Guggisberg (1869 - 1930)}

The Korle-Bu Teaching Hospital is one of several monuments in Ghana representing the outstanding contributions of Sir Frederick Gordon Guggisberg (1869 - 1930). A Canadian born, British colonial administrator, he served as Governor of the Gold
Britain. Guggisberg was subsequently educated in Britain and served in the colonial administration, rising from the rank of Second Lieutenant of the Royal Engineers to that of Brigadier General. While having served in Singapore, Nigeria and Guiana, he spent 14 years in the Gold Coast (Ghana), including first as a Surveyor (1902 - 1908) and then as Governor (1919 - 1927). As a surveyor, Guggisberg bequeathed the country and the world with an accurate map of Ghana.

\section{Beginning of Korle-Bu Teaching Hospital}

To improve public health, Guggisberg focused on sanitation and on pipe-borne water supply for Accra, Sekondi, Winneba and Kumasi. The population of Ghana at that time was 2.3 million people with 44,000 people living in Accra. Guggisberg extended medical services to other areas to provide care for the indigenous population, but concomitantly recognized the primary need for a large, modern hospital fully equipped for the care of the sick and for training of local health personnel for the health services. The outcome of this need was the building in 1923 of the Korle-Bu Hospital then known as the Gold Coast Hospital. The new hospital claimed to be the finest in Africa with room for 200 inpatients. "Before Guggisberg, the few hospitals in the country were located in the bigger towns having substantial European populations. Indeed, some of these were

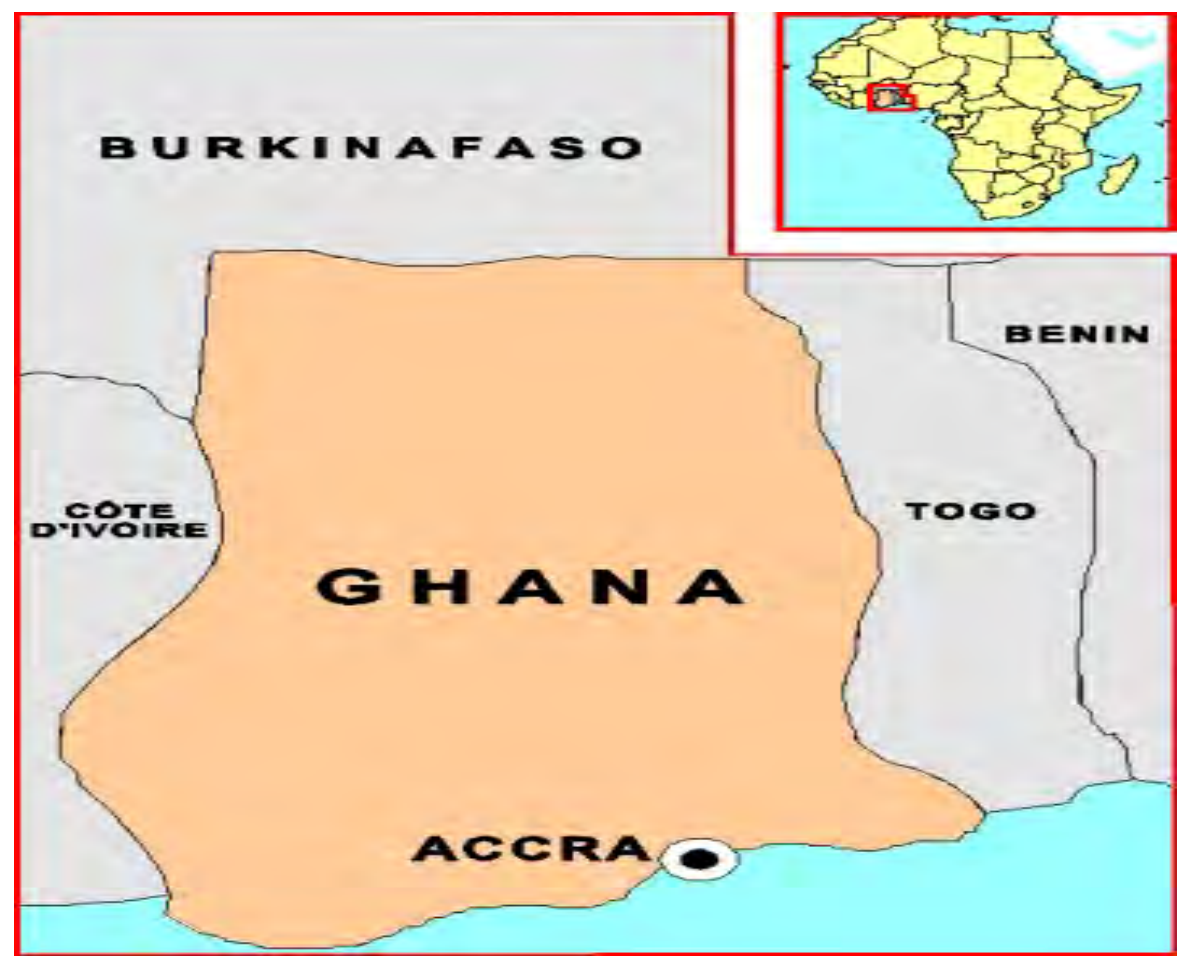

Coast from 1919 - 1927. Sir Gordon Guggisberg invested his life fully to lay a solid foundation upon which Ghana has been built. Gordon Guggisberg was born in Galt, Ontario, Canada. At the age of nine his widowed mother remarried and his stepfather, English Admiral Ramsey Dennis moved the family to Great built exclusively for European patients, and right up to the eve of Ghana's independence were referred to as "European Hospitals. Korle-Bu became the 'general' and model hospital for the entire nation, to which very serious cases needing skilled, specialist treatment were referred. 
Guggisberg envisioned that Korle-Bu Hospital would one day become a foremost medical school training young men and women as doctors in their own land, instead of going abroad. Nearly 160 acres of land in the vicinity were subsequently secured for future expansion. After gaining national independence in 1957, the Medical School and other health institutions would be established at Korle-Bu site. At the 50th Anniversary of Korle-Bu Teaching Hospital in 1973, the Health Commissioner shared that "it is appropriate that at this juncture we should pay tribute to those men and women through whose vision, determination and efforts these improvements in the health service have been made possible. .. the greatest tribute we can pay... therefore is to make Korle-Bu truly the greatest medical institution in Africa and one of the greatest in the world. . . It should be our aim to make anyone entering this hospital feel that he is within the confines of a unique and historic institution. We must create a new confidence in our people that in Korle-Bu we have the finest source for the restoration of good bealth to our sick people." other para medical staff. In 1946, a Nurses Training College was opened at Korle $\mathrm{Bu}$ to train a higher level of Staff Registered Nurses (SRNs) for the hospital, and for the entire country. Throughout the 1920s, there was a running debate among the medical establishment about whether the hospital should also be training doctors and medical assistants. In April 1963, this debate was permanently settled by a decision taken by the government to make Korle Bu Hospital the teaching hospital for the University of Ghana Medical School, until a medical center could be built at Legon (the main campus of the University of Ghana). The medical center in Legon never materialized, and, subsequently, the medical school was attached to Korle Bu hospital. From 1957 onwards, a rapid development and expansion of Korle Bu's original design - aimed at modernizing the hospital - has taken place. The expansion of the hospital resulted in an increase in the number of beds to 1526 by 1972 . Several specialties and sub-specialties, befitting the status of

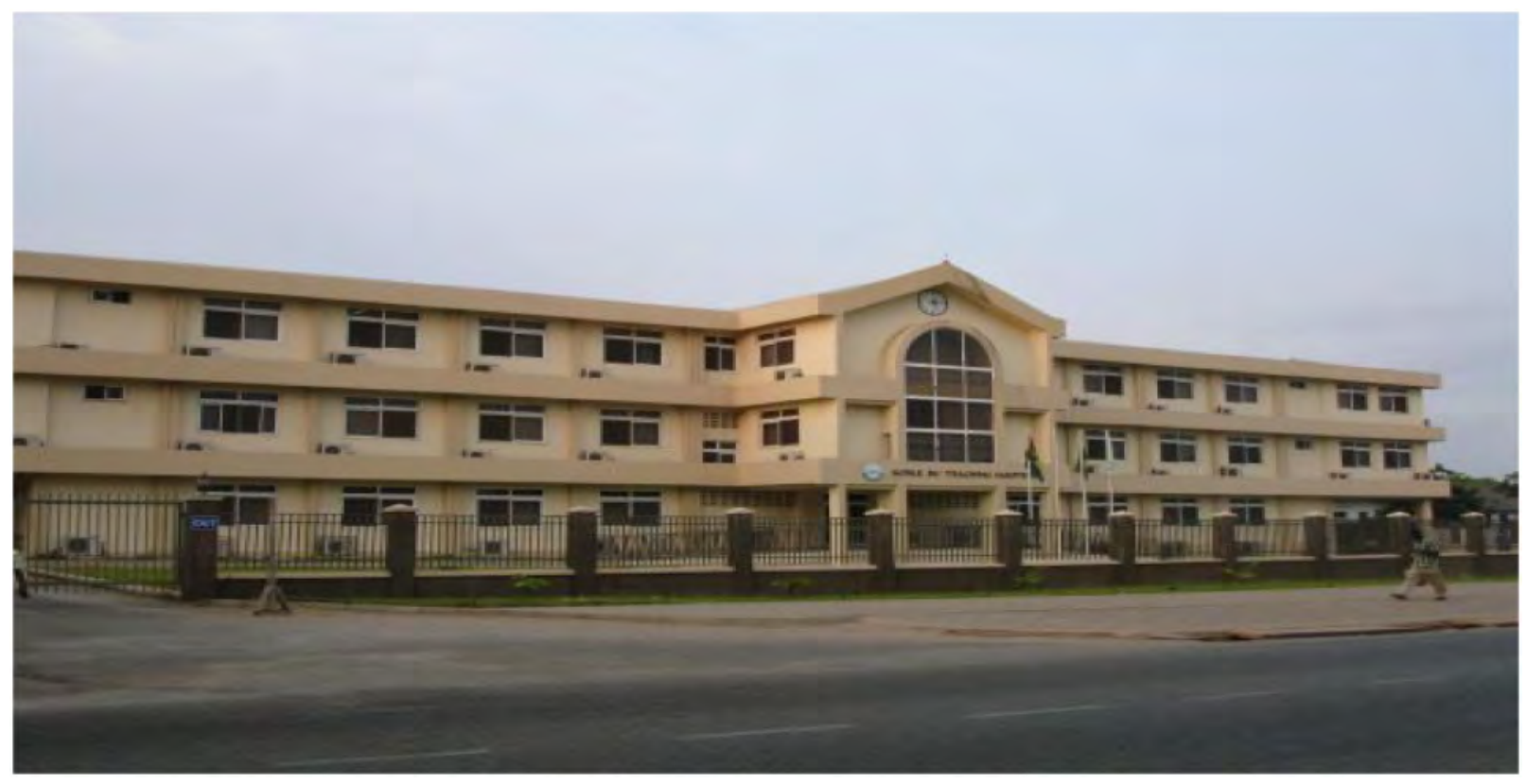

Korle Bu Teaching Hospital

\section{Korle Bu Teaching Hospital}

The Korle Bu Teaching Hospital, formerly known as the Gold Coast Hospital, was opened at its present site, in the south-western part of the city of Accra, on October 19, 1923 by the then Governor of the Gold Coast, Sir Gordon Guggisberg. At its inception, Korle Bu Hospital had less than 200 beds and treated up to 200 patients daily. At that time, Korle Bu was described as the finest hospital in Africa, on account of its impressive array of fine buildings and a cadre of competent staff, who provided excellent medical care to the population of Ghana, in general, and the city of Accra, in particular. Korle Bu Hospital, from its inception, has been used for the training of practical nurses, nurse-anaesthetists, dispensers, midwives and
Korle $\mathrm{Bu}$ as the apex tertiary care center in Ghana, were added to the traditional departments of Medicine, Surgery, Pediatrics and Obstetrics and Gynecology. Today, the Korle Bu Teaching Hospital has nearly 1600 beds (1995 estimates). It functions as the teaching hospital for the Ghana Medical School, and has a staff component of more than one hundred and fifty doctors. Korle Bu Hospital serves as the ultimate referral institution for patients from all over the country. It is also a general hospital for the Greater Accra Municipality which has an estimated population of 2.14 million (1993 projection from 1984). The hospital belongs to, and is controlled by, the Ministry of Health, although moves have been afoot for the last few years 
to make it a fully autonomous institution within the Ministry of Health. As a teaching hospital, Korle Bu has three primary goals: the provision of high-quality medical care, teaching (including the training of students in medicine, nursing, pharmacy, and a variety of other para-clinical and technical disciplines), and research) The hospital has specialised units in Surgery, Medicine, Paediatrics, Obstetrics and Gynaecology, Dentistry, Ophthalmology, Ear, Nose and Throat, Orthopaedics, Pathology and Communicable Diseases. Within the surgery department, the main divisions are the Units of General Surgery; Oral, Dental and Maxillo-facial Surgery; Cardio-Thoracic and Vascular Surgery; Neuro-Surgery; Uro-genital Surgery; and Casualty. Similarly, within the medicine department, the main divisions are the Units of General Medicine; Infectious Diseases; Cardiovascular Diseases; Emergency Medicine; Endocrine/Genetic Diseases; Kidney Diseases; Neurology; and Dermatology. The other large departments include Laboratory Services, the Blood Bank, Radiography, Physiotherapy, Occupational Health, and the Pharmacy department. There are a number of other institutions, with links to the Ministry of Health, located at Korle Bu. These are: The Nurses Training School, The Public Health Nurses Training School, The Midwifery Training School, The School of Hygiene, The Disease Control Division of the $\mathrm{MOH}$, The Health Education Unit of the $\mathrm{MOH}$, and The Center for Health Statistics of the MOH. In addition, several other institutions, with their own administration and budgets, have links with Korle $\mathrm{Bu}$ hospital. These include: The University of Ghana Medical School, The Blood Bank, The Health Laboratory Services, and The Public Health Reference Laboratory. Furthermore, there are other governmental institutions like the Public Works Department that are located within Korle-Bu and provide general services to it, but do not come under the hospital's control at all.

\section{Ghana Medical Journal}

The Ghana medical Journal is the Nation's top peerreview medical journal. A review of the contents of this journal showed that Ghanaian medical scientists have written prominent papers in the fields of cardiovascular medicine, hypertension, infectious diseases (especially hepatitis), communicable and parasitic diseases (including malaria), sickle cell anemia and other hemoglobinopathies, clinical surgery and surgical subspecialties.

Ghana and Great Medical Textbooks of Africa In his preface to Principles of Medicine in Africa edited by E.H.O. Parry, the then Deputy-General of the World Health Organization Prof. T. Adeoye Lambo, had this to say: "Until recently the practitioner in Africa had to rely on texts that have been written in an environment that is very different from his own. He would supplement the general medical texts with books on tropical medicine, but the latter concentrated mainly on the description of parasitic and infectious disease that are peculiar to hot climates. And yet, he needs guidance on how to cope with non-communicable diseases like hypertension, diabetes, and other disorders of endocrine functions, as well as psychiatric disorders. Many of these present different manifestations in the African and require modifications of therapeutic measures that have been developed elsewhere to suit the local situation. Such modifications have to take note of differences in the genetic background and nutritional status of the host as well as the coexistence of other diseases. In recent years with the development of academic medicine in Africa, new medical texts are appearing to fill this gap. Local relevant experience is being gathered and synthesized for the guidance of practitioners and students alike. This book is an example of this new trend having been written by authors who have had first-hand experience and intimate knowledge of medical practice in Africa. They are colleagues of bigh academic stature and versatile clinicians and observers."

The Ghana medical school produced two notable books that continue to make impact in the training of medical doctors in Africa. Principles of Medicine in Africa by E.H.O. Parry was first published in 1976. The other great book is Principles and Practice of Surgery including Pathology in the Tropics by Badoe, Achampong and Jaja first published in 1986. On page 112 of the third edition of the book published in the year 2000, a table of some intravenous infusion fluids shows the composition of the Korle bu solution (Badoe's maintenance solution). With these books Medical education in Africa received a tremendous boost in the quality of undergraduate and postgraduate training and medical care and as a result many other notable books have been written by Africans. Books, more than anything else, tell the stories of institutions, men and women.

\section{Nigeria and her Teaching Hospitals}

Nigeria was once the most advanced black nation in Africa and still has the potential of ranking amongst the five most advanced nations in the World. The country once laid claims to having the best universities and teaching hospitals in the Commonwealth of Nations. No nation of Africa will ever have the human resources that Nigeria has and it would take approximately fifty years for other West and Central African Nations to achieve the infrastructural development that Nigeria achieved post-independence. While these are facts the nation has continued to lose most of the positive achievements she had a few decades ago. This decay can be directly linked to the greed that has eaten deep into almost every citizen of the country. The desire for more money by the working 
populace without corresponding increase in services must be checked at the individual level.

Our institutions and teaching hospitals can regain their top positions in the continent very easily if visionary leaders pursue a culture of positive change and excellence. Amongst the great teaching hospitals of Africa is the University College Hospital (UCH) Ibadan. The University College Hospital (UCH) Ibadan has many similarities to Korle Bu teaching hospital. UCH is a hospital with a long history of very great achievements and by the astute vision of the present management she is being repositioned to regain and surpass past glory and attain the fullness of her potential. There is no doubt that the hospital at Ibadan has always had the potential of becoming the greatest and finest hospital in Africa. Recently the hospital has witnessed positive restructuring, enlargement, and changes that are destined to position her as one of the most prestigious teaching hospitals in Africa and a center of excellence by every international standard.

The history of this great hospital has been well documented; what is exciting is the future of the hospital in light of the ongoing major transformation. In the future editions of this journal Chronicles of medical bistory in Africa will examine closely the challenges and triumphs of UCH in the recent years and her journey back to prominence and greatness. Chronicles of medical bistory in Africa plans to expand this series on great teaching hospitals in Africa to cover all the teaching hospitals in Nigeria and those in other Nations of Africa that have made impact on medical education and health care in Africa. Every teaching hospital has the potential of affecting the destinies of Nations.

\section{REFERENCES}

1. Korle $\mathrm{Bu}$ Teaching Hospital; http:// en.wikipedia.org/wiki/Korle_Bu_Teaching _Hospital

2. Founder of Korle Bu Teaching Hospital; http:// $\mathrm{kbnf}$.org/index.php?option =com_content $\&$ view $=$ article $\&$ id $=83 \&$ Itemid $=55$

3. List of university hospitals; http:// en.wikipedia.org/wiki/List_of_university_ hospitals

4. Hospital autonomy in Ghana: the experience of Korle Bu and Komfo Anokye Teaching Hospitals; http: / / $209.85 .229 .132 /$ s e a r c ? q= cache:JNAHIBdhp80J:www.hsph.harvard.edu/ ihsg/publications/pdf/No-41.PDF+J+Hawe+ korle + Bu\&cd $=1 \& h l=$ en\&ct $=$ clnk\&gl=ng

5. Ghana medical journal http:// www.pubmedcentral.nih.gov/tocrender.fcgi?iid $=141949$ 